\title{
On the Origin of the Surface Air Temperature Difference between the Hemispheres in Earth's Present-Day Climate
}

\author{
Georg Feulner, Stefan Rahmstorf, Anders Levermann, and Silvia Volkwardt \\ Earth System Analysis, Potsdam Institute for Climate Impact Research, Potsdam, Germany
}

(Manuscript received 28 August 2012, in final form 5 March 2013)

\begin{abstract}
In today's climate, the annually averaged surface air temperature in the Northern Hemisphere (NH) is $1^{\circ}-2^{\circ} \mathrm{C}$ higher than in the Southern Hemisphere $(\mathrm{SH})$. Historically, this interhemispheric temperature difference has been attributed to a number of factors, including seasonal differences in insolation, the larger area of (tropical) land in the NH, the particularities of the Antarctic in terms of albedo and temperature, and northward heat transport by ocean circulation. A detailed investigation of these factors and their contribution to the temperature difference, however, has to the authors' knowledge not been performed so far. Here the origin of the interhemispheric temperature difference is traced using an assessment of climatological data and the observed energy budget of Earth as well as model simulations. It is found that for the preindustrial climate the temperature difference is predominantly due to meridional heat transport in the oceans, with an additional contribution from the albedo differences between the polar regions. The combination of these factors (that are to some extent coupled) governs the evolution of the temperature difference over the past millennium. Since the beginning of industrialization the interhemispheric temperature difference has increased due to melting of sea ice and snow in the NH. Furthermore, the predicted higher rate of warming over land as compared to the oceans contributes to this increase. Simulations for the twenty-first century show that the interhemispheric temperature difference continues to grow for the highest greenhouse gas emission scenarios due to the land-ocean warming contrast and the strong loss of Arctic sea ice, whereas the decrease in overturning strength dominates for the more moderate scenarios.
\end{abstract}

\section{Introduction}

"In few departments of Natural Philosophy have Philosophers differed more widely in opinion, than in the comparison of the temperatures of the two hemispheres." (Harvey 1834, p. 29). Indeed, the scientific debate on the surface air temperature difference between Earth's hemispheres and its causes has a long and rich history that can be traced back to the beginning of the sixteenth century. When the early navigators explored the higher latitudes of the Southern Ocean, their reports suggested cooler conditions than the ones found at equivalent latitudes in the Northern Hemisphere (NH). Therefore, the notion of the Southern Hemisphere ( $\mathrm{SH}$ ) being much colder than the Northern Hemisphere on annual average developed [see the discussions in Kirwan (1787),

Corresponding author address: Georg Feulner, Earth System Analysis, Potsdam Institute for Climate Impact Research, P.O. Box 6012 03, D-14412 Potsdam, Germany.

E-mail: feulner@pik-potsdam.de von Humboldt (1817), and Harvey (1834)], although there were hardly any measurements to support this hypothesis.

One reason for possible differences in average hemispheric surface air temperatures already suggested in the eighteenth century are differences in seasonal insolation arising from the fact that Earth is closer to the sun during austral summer, passing the point of minimum distance (perihelion) on its elliptical orbit in the beginning of January.

Although in the meantime debated on inaccurate theoretical grounds, the notion of a colder Southern Hemisphere was confirmed by the increasing availability of meteorological measurements from both hemispheres in the nineteenth century. One of the more prominent scientists investigating this phenomenon was Alexander von Humboldt, who attributed the temperature difference to the larger tropical land area in the Northern Hemisphere (von Humboldt 1817). Under equal solar radiation, land tends to be warmer than the ocean. It was argued that this effect would lead to warmer tropical 
latitudes in the Northern Hemisphere and thus at least contribute to a positive temperature difference between the Northern and the Southern Hemisphere.

Furthermore, an influence of ocean currents on the latitudinal distribution of surface air temperatures on Earth was already suggested in the nineteenth century (Croll 1870; Zenker 1888), in particular the effect of the Gulf Stream on temperatures in the Northern Hemisphere.

By the beginning of the twentieth century, a small temperature difference of $1^{\circ}-2^{\circ} \mathrm{C}$ between the Northern and Southern Hemispheres was well established in meteorology (Lockyer 1906). It should be noted that this value of the hemispheric temperature difference is already remarkably close to the one derived from modern measurements discussed later in this paper.

The marked difference between surface temperatures in the Antarctic and the Arctic was discussed as an additional factor in the asymmetry between Earth's hemispheres in the following decades (e.g., Flohn 1981). The differences between Earth's polar regions are mainly due to geography: while the Arctic comprises a partly icecovered ocean surrounded by continents, its southern equivalent consists of the continent of Antarctica, which is continuously covered by ice and surrounded by open ocean.

In this brief journey through history, we have already encountered several possible contributing factors for the warmer Northern Hemisphere: Differences in seasonal insolation, the influence of the Antarctic, the different distribution of landmasses (in particular in the tropics), and finally a possible contribution of ocean currents transporting warmer water from the Southern Hemisphere across the equator. These suggested causes are still listed in modern textbooks. A systematic assessment of the contribution of these factors to the hemispheric temperature difference, however, has to the best of our knowledge not been performed so far and will be presented in this work.

Note that the interhemispheric temperature difference is not of purely academic interest since it has farreaching implications for global weather patterns, in particular for tropical rainfall variability (e.g., Chiang and Friedman 2012). This is of particular importance because observations and model simulations of future climate change indicate an increase of the temperature difference between the Northern and Southern Hemisphere under global warming (e.g., Stouffer et al. 1989; Washington and Meehl 1989), a phenomenon that has been attributed to the decline in sea ice and snow cover in the Northern Hemisphere and the larger thermal inertia of the Southern Hemisphere due to its smaller land fraction (a transient effect).
A further contribution to the increase of the temperature difference between the hemispheres under global warming arises from the larger land fraction in the Northern Hemisphere combined with the robust prediction of an enhanced temperature contrast between land and oceans in a warming climate (e.g., Manabe et al. 1991). A variety of factors contributing to this phenomenon have been identified, including ocean heat uptake (Lambert and Chiang 2007), limits to evaporation over the comparatively dry land surface (Sutton et al. 2007), differences in changes to the lapse rate over oceans and land (Joshi et al. 2008), and radiative and cloud feedbacks (Shimpo and Kanamitsu 2009; Fasullo 2010).

This paper is organized as follows. After the introduction, section 2 describes the observed temperature difference between Earth's hemispheres. The influence of elevation on the interhemispheric temperature difference is analyzed in section 3 . The effects of the distribution of tropical landmass on surface temperature are described in section 4 . Section 5 investigates whether differences in top-of-atmosphere (TOA) insolation could be responsible for hemispheric temperature differences, while section 6 takes a look at the energy budget of both hemispheres in terms of absorbed shortwave and emitted longwave radiation. Meridional heat transport, in particular by the oceans, is discussed in section 7 , both from an observational point of view and using climate model experiments. Changes in time of the interhemispheric temperature difference during the last millennium and for various scenarios for future climate change are discussed in section 8. Finally, the results are summarized and discussed in the conclusions (section 9).

\section{The observed temperature difference}

Observational data show a clearly asymmetric distribution of annually and zonally averaged surface air temperatures around the equator. These averages of the 2-m temperature as a function of latitude are shown in Fig. 1 for the absolute temperatures of the Climatic Research Unit (CRU) climatology in the time period 1961-90 (data retrieved from http://www.cru.uea.ac.uk/ cru/data/temperature/ on 15 April 2010; Jones et al. 1999) as well as for the National Centers for Environmental Prediction (NCEP; data retrieved from ftp://ftp. cdc.noaa.gov/Datasets/ncep.reanalysis.derived/surface/ on 16 April 2010; Kalnay et al. 1996) and the 40-yr European Centre for Medium-Range Weather Forecasts (ECMWF) Re-Analysis (ERA-40; data retrieved from http://data-portal.ecmwf.int/data/d/era40/ on 19 April 2010; Uppala et al. 2005) reanalysis datasets evaluated during the same period. The three datasets 


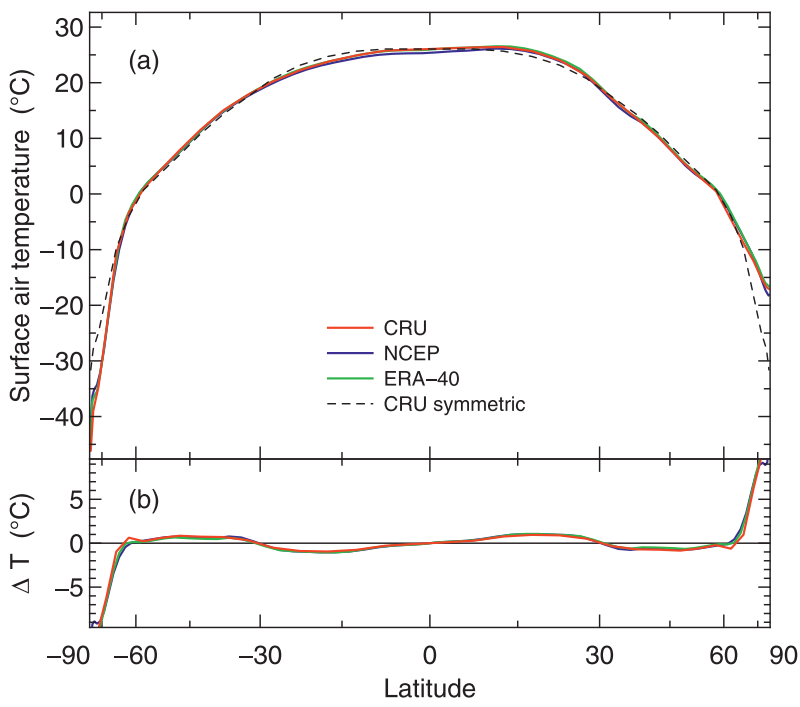

FIG. 1. (a) Annual average of surface air (2 m) temperatures for the time period 1961-90 as a function of latitude for the CRU climatology (red) as well as the NCEP (blue) and ERA-40 (green) reanalysis datasets. A temperature distribution symmetric about the equator constructed by taking the mean of the CRU temperatures in the $\mathrm{NH}$ and $\mathrm{SH}$ for each latitude is also shown (black dashed line) to highlight where the curves deviate from symmetry. (b) As in (a), but showing the difference from a symmetrized temperature distribution for each dataset. Equal intervals on the latitude axis correspond to equal areas on the globe.

show very good general agreement, with minor differences in the tropics and, not surprisingly, slightly larger offsets in the polar regions. The latter, however, do not strongly affect hemispheric averages due to their comparatively small contribution in terms of area.

The general shape of this latitudinal temperature distribution shows a slightly tilted plateau in the tropics with a maximum at about $10^{\circ} \mathrm{N}$ as well as the well-known difference between the much colder Antarctic and the Arctic. The location of the maximum of the temperature distribution is closely connected to the mean position of the intertropical convergence zone (ITCZ), which lies just north of the equator, although local factors clearly influence the location of the ITCZ as well (e.g., Philander et al. 1996).

Averaged over the year, the Northern Hemisphere is slightly warmer than the Southern Hemisphere (see Table 1). Depending on the dataset, the annually averaged surface air temperature is $1.2^{\circ}-1.5^{\circ} \mathrm{C}$ higher in the Northern Hemisphere. Seasonal variations of this difference are strong, of course, ranging from about $-7.5^{\circ} \mathrm{C}$ in $\mathrm{NH}$ winter [December-February (DJF)] to about $10^{\circ} \mathrm{C}$ in $\mathrm{NH}$ summer [June-August (JJA)]. And while the interhemispheric surface temperature difference vanishes in NH spring [March-May (MAM)], there is a pronounced difference of about $3^{\circ} \mathrm{C}$ during $\mathrm{NH}$ autumn
TABLE 1. Annual and seasonal values for global and hemispheric averages of the surface air temperature as well as the difference between the Northern and the Southern Hemisphere for different observational datasets. The last column lists the hemispheric temperature difference corrected for the effect of elevation as discussed in the text.

\begin{tabular}{llcrccc}
\hline \hline Period & Dataset & $T_{\text {global }}$ & $T_{\mathrm{NH}}$ & $T_{\mathrm{SH}}$ & $\Delta T_{\mathrm{NH}-\mathrm{SH}}$ & $\Delta T_{\mathrm{NH}-\mathrm{SH}}^{\text {corr. }}$ \\
\hline Annual & CRU & 14.0 & 14.6 & 13.3 & 1.2 & 1.2 \\
& NCEP & 13.8 & 14.5 & 13.1 & 1.4 & 1.3 \\
& ERA-40 & 14.1 & 14.9 & 13.4 & 1.5 & 1.5 \\
DJF & CRU & 12.2 & 8.5 & 16.0 & -7.5 & -7.6 \\
& NCEP & 12.3 & 8.6 & 16.0 & -7.4 & -7.5 \\
& ERA-40 & 12.5 & 8.8 & 16.2 & -7.4 & -7.5 \\
MAM & CRU & 13.9 & 13.8 & 13.9 & -0.1 & -0.2 \\
& NCEP & 13.6 & 13.7 & 13.6 & 0.1 & 0.0 \\
& ERA-40 & 14.1 & 14.2 & 14.0 & 0.2 & 0.1 \\
JJA & CRU & 15.7 & 20.4 & 11.0 & 9.5 & 9.4 \\
& NCEP & 15.3 & 20.3 & 10.3 & 10.0 & 10.0 \\
\multirow{5}{*}{ SON } & ERA-40 & 15.8 & 20.8 & 10.8 & 10.0 & 9.9 \\
& CRU & 14.1 & 15.6 & 12.5 & 3.1 & 3.0 \\
& NCEP & 13.8 & 15.2 & 12.3 & 2.9 & 2.9 \\
& ERA-40 & 14.2 & 15.8 & 12.5 & 3.3 & 3.2 \\
\hline
\end{tabular}

[September-November (SON)]. We will come back to this observation in the discussion in section 9. The seasonal distributions of zonally averaged surface temperatures are shown in Fig. 2.

\section{The influence of elevation}

In the upper panel of Fig. 3 we show a global map of the surface air temperatures from the CRU dataset. The effect of land (and ice sheet) elevation combined with the lapse rate on the temperature distribution is immediately apparent, making Antarctica, Greenland, and the large mountain ranges markedly cooler than their surroundings.

To investigate the influence of this elevation effect on the hemispheric temperature difference, we correct for this by computing sea level temperatures using an elevation map (the elevation map is regridded from the U.S. Navy 10-arcmin elevation map available at http:// rda.ucar.edu in dataset number ds754.0; date of access 8 March 2011) and a moist-adiabatic lapse rate of $5^{\circ} \mathrm{C} \mathrm{km}^{-1}$ everywhere except for Antarctica, where a dry-adiabatic lapse rate of $9.8^{\circ} \mathrm{C} \mathrm{km}^{-1}$ is assumed. The resulting geographic distribution of surface air temperatures extrapolated to sea level is presented in the middle panel of Fig. 3. Note the slightly lower temperatures over Antarctica as compared to the Arctic, the cooling influence of the eastern boundary currents, and the northward displacement of the isotherms over the North Atlantic due to the meridional overturning circulation. These effects are even more apparent in a map where for a given latitude $\varphi$ the average of the zonal 


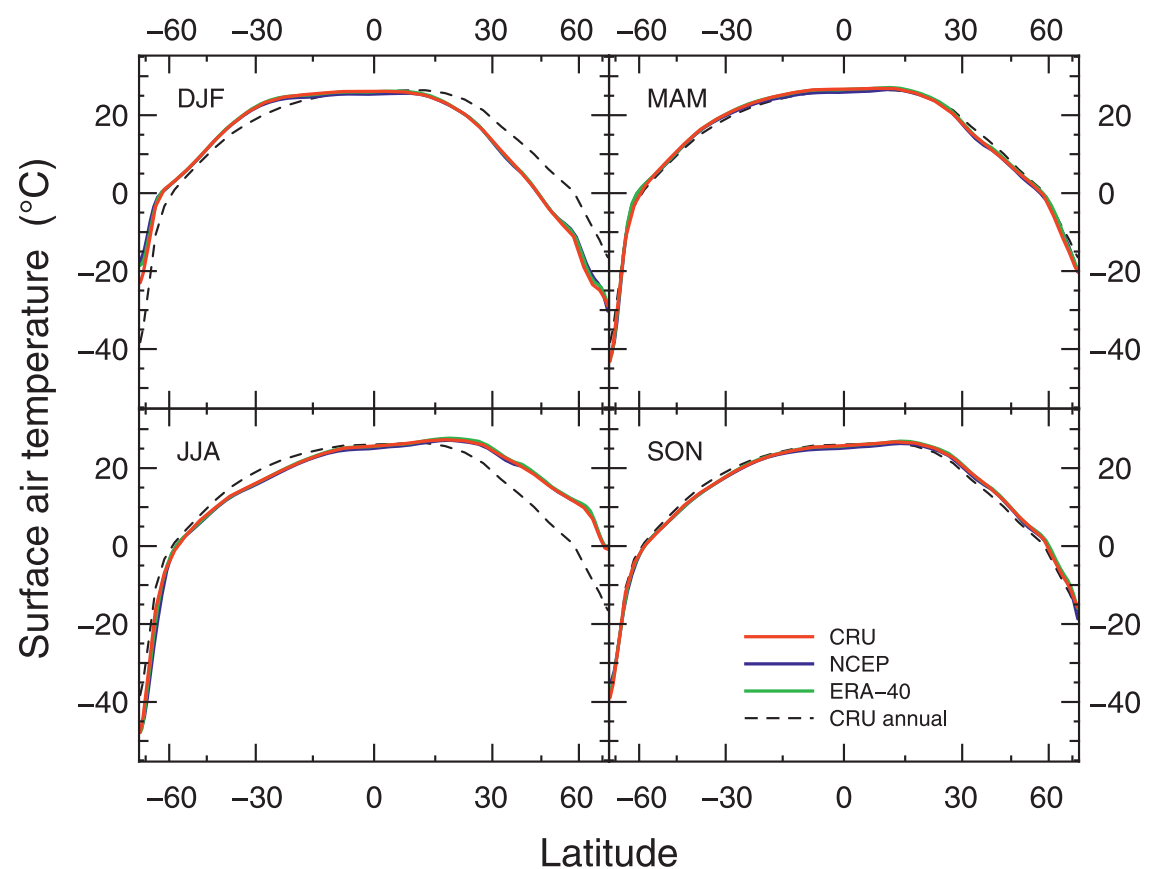

FIG. 2. As in Fig. 1, but for seasonal averages of the surface air $(2 \mathrm{~m})$ temperatures as a function of latitude. The different lines show the values for the CRU climatology (red) as well as the NCEP (blue) and ERA-40 (green) reanalysis datasets evaluated in the period 1961-90. The black dashed line indicates the annual temperature distribution from the CRU dataset. Equal intervals on the latitude axis correspond to equal areas on the globe.

mean temperatures for latitudes $\varphi$ and $-\varphi$ is subtracted (lower panel of Fig. 3). In particular, the pronounced warm anomaly over the North Atlantic should be noted. (The cooler areas in the northeastern parts of the North American and Eurasian continents appear so cool because the high temperatures over the North Atlantic strongly increase the zonal averages at these latitudes.)

The effect of this elevation correction on the observed surface air temperature distribution with latitude is shown in Fig. 5. The temperature difference between the Northern and Southern Hemispheres changes very little, however (by $\sim 0.1^{\circ} \mathrm{C}$; see Table 1 ), since the strong positive correction for Antarctica is compensated by the slightly warmer temperatures of the whole land surface (which covers a larger area in the Northern Hemisphere).

In the following sections we will analyze the various possible causes of the interhemispheric temperature difference in terms of observed temperatures and energy flows in the climate system. We begin with an analysis of the influence of the different distributions of continental area in both hemispheres.

\section{The effect of land on surface temperatures}

It has often been suggested that the larger fraction of tropical land north of the equator contributes to the positive temperature difference between Earth's hemispheres. The argument rests on the observation that land in the tropics (i.e., between latitudes $23.5^{\circ} \mathrm{S}$ and $23.5^{\circ} \mathrm{N}$ ) tends to be warmer than the oceans. Historically, this was mainly attributed to the smaller heat capacity of land, which results in a larger warming of land under equal amounts of solar radiation as compared to the oceans. This explanation is not convincing, however, because the effect is transient and vanishes when integrating over diurnal and annual cycles, and the factors discussed in section 1 in the context of the increasing land-ocean warming contrast should be more important in explaining warmer tropical land areas under equilibrium conditions.

In Fig. 4 the latitudinal distribution of surface air temperatures over land (adjusted for elevation) and oceans in the CRU data (Jones et al. 1999) is shown. The two most obvious features are the higher land temperatures in the tropics and the higher ocean temperatures in the NH midlatitudes.

Thus land areas in the tropics are indeed warmer than the oceans, but they have only a negligible influence on the interhemispheric temperature difference. While the surface air temperature difference between the $\mathrm{NH}$ and $\mathrm{SH}$ is $1.40^{\circ} \mathrm{C}$ for the tropical land areas (and $1.14^{\circ} \mathrm{C}$ in the elevation-corrected data), it is only slightly smaller 

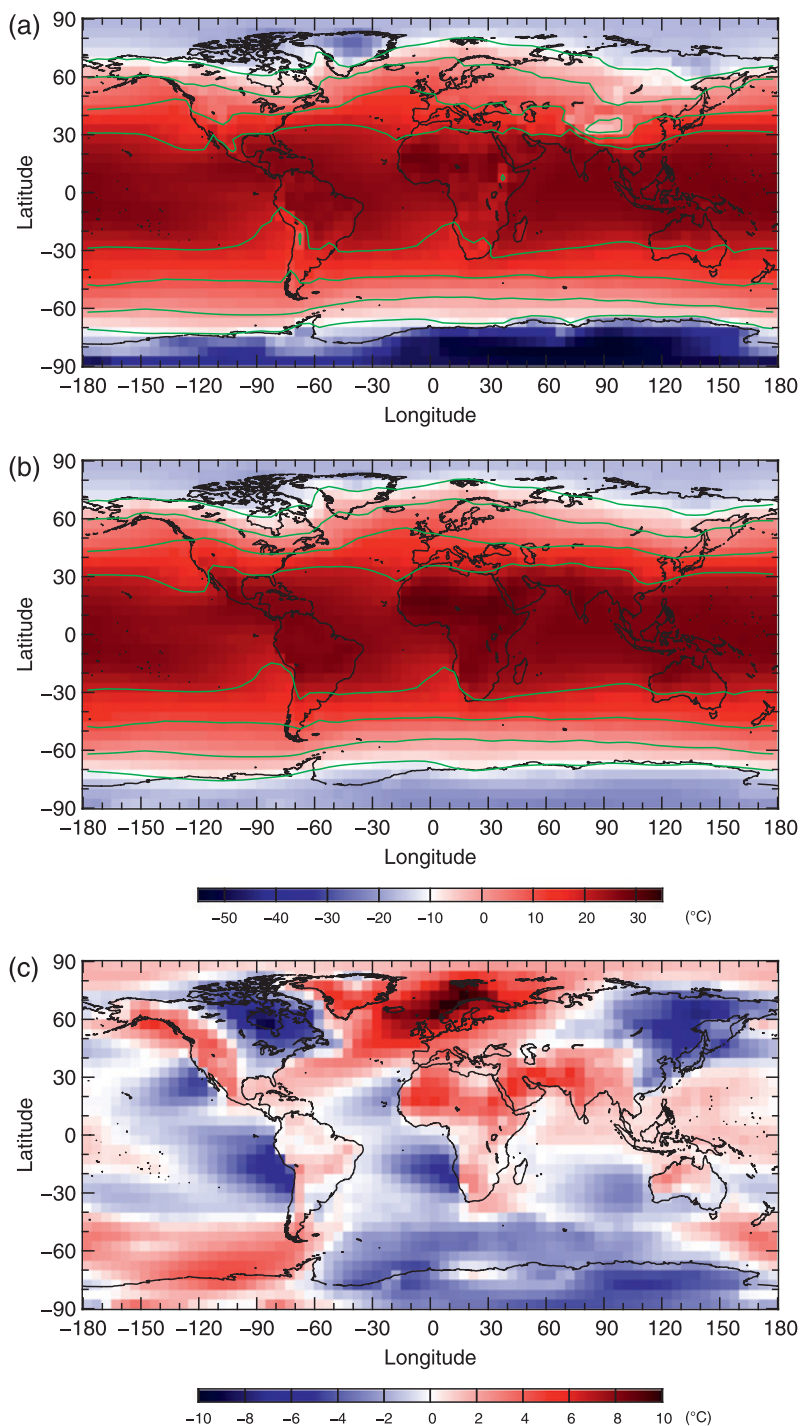

FIG. 3. (a) Map of annual averages of surface air temperatures for the time period 1961-90 from the CRU climatology. (b) As in (a), but corrected for the effects of land and ice-sheet elevation using a moist-adiabatic lapse rate of $5^{\circ} \mathrm{C} \mathrm{km}^{-1}$ everywhere except for Antarctica, where a dry-adiabatic lapse rate of $9.8^{\circ} \mathrm{C} \mathrm{km}^{-1}$ was assumed. The same color scale was used in both panels for clarity, and contour levels at $-10^{\circ}, 0^{\circ}, 10^{\circ}$, and $20^{\circ} \mathrm{C}$ are shown in green. (c) As in (b), but with zonal averages symmetric with respect to the equator subtracted.

$\left(0.97^{\circ} \mathrm{C}\right)$ for the tropical oceans. This small difference cannot substantially contribute to the overall hemispheric temperature contrast.

Moreover, the situation for the midlatitudes is completely different, with a large positive interhemispheric temperature difference of $5.20^{\circ} \mathrm{C}$ for the oceans contrasted by a large negative difference of $-6.80^{\circ} \mathrm{C}$ for the land areas (and $-4.88^{\circ} \mathrm{C}$ for CRU data corrected for elevation effects). These large differences result both

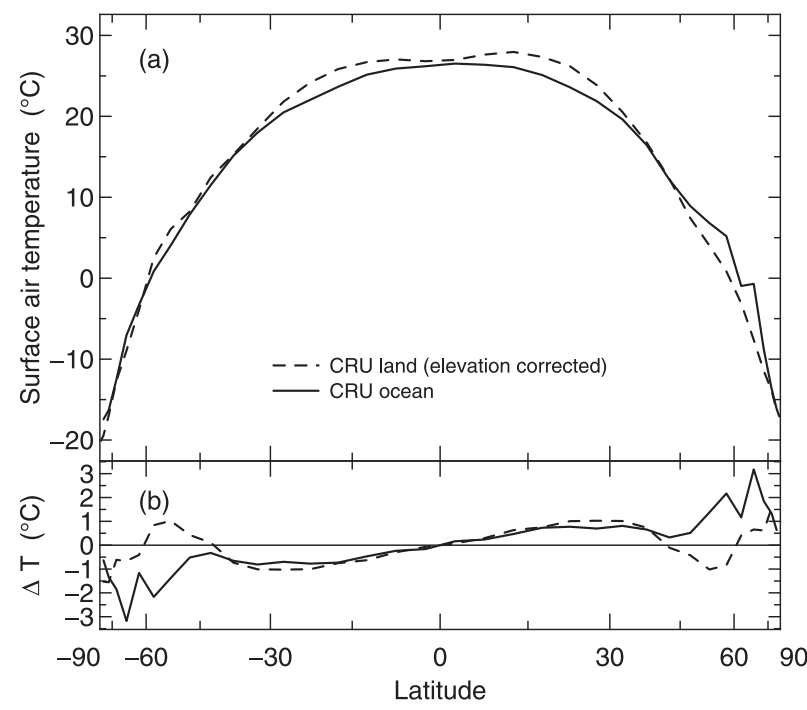

FIG. 4. (a) Surface air temperature as a function of latitude for land (dashed line, corrected for elevation) and ocean (solid line) from the CRU climatology for the years 1961-90. (b) As in (a), but showing the difference from a symmetrized temperature distribution for each dataset. Equal intervals on the latitude axis correspond to equal areas on the globe.

from the warmer North Atlantic and from the much higher fraction of continental area at high latitudes in the Northern Hemisphere (see lower panel of Fig. 3).

For the whole hemispheres, the $\mathrm{NH}$ oceans are warmer by $4.24^{\circ} \mathrm{C}$ in the CRU data, while the land areas exhibit an interhemispheric temperature difference of only $0.74^{\circ} \mathrm{C}\left(-1.13^{\circ} \mathrm{C}\right.$ in the elevation corrected data). It is thus the surface temperatures over the oceans rather than the land areas that are responsible for the temperature difference between the two hemispheres.

Note, however, that there are a number of factors resulting in an increase of the land-ocean contrast in surface air temperatures under global warming (see the discussion in section 1); we will come back to this issue in section 8 where we explore the future evolution of the interhemispheric temperature difference.

\section{Top-of-atmosphere insolation}

Historically, differences in the energy budget (and hence temperatures) of Earth's hemispheres have often been attributed to annual or seasonal differences in topof-atmosphere insolation.

At the top of the atmosphere, the hemispheres receive slightly different amounts of solar radiation in corresponding seasons due to the tilt of Earth's axis and the elliptical shape of its orbit. Specifically, Earth passes its perihelion (the point of closest approach to the sun) in the beginning of January, very close to winter solstice in 
the Northern Hemisphere. This has two competing implications for seasonal hemispheric insolation. On the one hand, Earth is closer to the sun during SH summer and thus receives more radiation per unit of time than during $\mathrm{NH}$ summer. On the other hand, because of Kepler's second law Earth moves faster on its orbit around the time of perihelion (and slower around its aphelion, when Earth is farthest from the Sun), so SH summer is shorter than its $\mathrm{NH}$ equivalent.

These two effects cancel each other when integrating the insolation $Q_{\mathrm{NH}, \mathrm{SH}}(t)$ as a function of time $t$ for the Northern and Southern Hemispheres over one year (Lambert 1779; Milankovitch 1941; Loutre et al. 2004), yielding

$$
Q_{\mathrm{NH}, \mathrm{SH}}^{\mathrm{ann}}=\frac{S \pi R^{2} T}{2 \sqrt{1-e^{2}}}
$$

where $S$ is the solar constant, $R$ is Earth's radius, $T$ is Earth's orbital period, and $e$ is the orbit's eccentricity.

Note that the integrals of the annual TOA insolation of Earth's hemispheres have exactly the same values. For a solar constant $S=1365 \mathrm{~W} \mathrm{~m}^{-2}$ this corresponds to 87.4 PW insolation for each hemisphere or $174.8 \mathrm{PW}$ globally $\left(1 \mathrm{PW}=1 \times 10^{15} \mathrm{~W}\right)$. Both hemispheres are thus expected to receive exactly equal amounts of solar radiation at the top of the atmosphere over the course of one year.

Nevertheless, the seasonal variations in TOA insolation could in principle cause differences in absorbed solar radiation when combined with seasonal albedo variations. It will be shown below, however, that both hemispheres absorb roughly equal amounts of solar radiation over the course of one year. Hence it is clear that TOA insolation cannot explain the observed temperature contrast between the Northern and Southern Hemispheres.

It is interesting to compare the theoretical calculation for the annual TOA insolation with observational data. Here and in the following we will use satellite observations to analyze measured energy flows in the earth system. Specifically, we use the long-term means derived from data of the Clouds and Earth's Radiative Energy System (CERES; Wielicki et al. 1996) experiment (Fasullo and Trenberth 2008; data retrieved from ftp://ftp.cgd. ucar.edu on 25 March 2010). These data span the time period from March 2000 to May 2004 and will be referred to as CERES-FT08 in the following. We have limited our analysis to data from the CERES flight model 1 (FM1) launched on board the Terra satellite as this is considered the most reliable version of the experiment (J. Fasullo 2010, personal communication) and differences between the four flight models are relatively
TABLE 2. Summary of Earth's global and hemispheric energy flows $F$ [based on the CERES-FT08 dataset described in Fasullo and Trenberth (2008)] at the top of the atmosphere. The table lists global values $F_{\text {global }}$, hemispheric values for the $\mathrm{NH} F_{\mathrm{NH}}$ and the SH $F_{\mathrm{SH}}$ as well as the difference $\Delta F_{\mathrm{NH}-\mathrm{SH}}$ between the $\mathrm{NH}$ and the SH. All values are given in PW $\left(10^{15} \mathrm{~W}\right)$; quoted numbers are optimized for readability rather than comparability of significant digits.

\begin{tabular}{lrrrc}
\hline \multicolumn{1}{c}{ Quantity } & $F_{\text {global }}$ & $F_{\mathrm{NH}}$ & $F_{\mathrm{SH}}$ & $\Delta F_{\mathrm{NH}-\mathrm{SH}}$ \\
\hline Top-of-atmosphere insolation* & 174.8 & 87.3 & 87.5 & -0.2 \\
Reflected solar radiation & 52.2 & 26.0 & 26.1 & -0.1 \\
Incoming solar radiation & 122.6 & 61.3 & 61.3 & -0.1 \\
Outgoing longwave radiation & 122.1 & 61.2 & 60.9 & 0.3 \\
Radiative imbalance & 0.5 & 0.1 & 0.4 & -0.4 \\
\hline
\end{tabular}

* Theoretically, the difference in the top-of-atmosphere insolation between the two hemispheres should be zero; see section 5 for discussion.

small. In addition, we will make use of the CERES-Energy Balanced and Filled (EBAF) dataset (data retrieved from http://eosweb.larc.nasa.gov on 15 June 2010) for top-of-atmosphere fluxes (Loeb et al. 2009), which generally agrees very well with CERES-FT08 after correcting for the difference in the solar constant assumed in the datasets.

Contrary to the theoretical expectations discussed above, satellite data from both the CERES-FT08 and CERES-EBAF products show an imbalance with the Southern Hemisphere receiving about $0.2 \mathrm{PW}$ more radiation (see Table 2). Exploring the reason for this discrepancy is, however, beyond the scope of this paper. In any case, this imbalance cannot explain a warmer Northern Hemisphere.

\section{Atmospheric energy balance}

\section{a. Reflected shortwave radiation}

As explained above, based on astronomical calculations Earth's two hemispheres receive equal amounts of 87.4 PW of energy from the sun. Part of this radiation is reflected back to space by clouds in the atmosphere and by the surface itself, quantified by the planet's albedo of about $30 \%$. According to the CERES-FT08 dataset, the reflected energy flows are 26.0 and 26.1 PW for the Northern and Southern Hemisphere, respectively (see Table 2).

The slightly larger total albedo of the Southern Hemisphere is caused by several factors. To begin with, the Southern Hemisphere reflects more radiation back to space due to a larger annual fraction of low clouds, which dominate the cloud-albedo effect (Hartmann et al. 1992). Indeed, for the time period 1961-90, the ERA-40 (Uppala et al. 2005) reanalysis dataset yields 
annually averaged low cloud cover fractions of 0.31 and 0.38 for the Northern and Southern Hemisphere, respectively, and the CERES-FT08 data show that the amount of radiation reflected by the Southern Hemisphere is larger by about $1.7 \mathrm{PW}$ due to this.

This higher atmospheric albedo in the $\mathrm{SH}$ is almost balanced by the lower surface albedo due to the larger area covered by oceans in the Southern Hemisphere, however. In the CERES-FT08 data, the surface in the Northern Hemisphere reflects roughly 1.6 PW more radiation than in the Southern Hemisphere due to this effect.

The higher average albedo of the Antarctic, which is often mentioned as one potential reason for the hemispheric temperature difference, plays a role here but obviously cannot compensate for the larger and comparatively dark areas of ocean in the SH.

Apart from the albedo, several factors arising from these differences in geography contribute to the much lower Antarctic surface air temperatures (King and Turner 1997), including the high elevation of Antarctica, the lack of heat transfer from a polar ocean as compared to the Arctic, and the isolating effects of the Antarctic circumpolar ocean current and the polar atmospheric vortex. Elevation is clearly very important for Antarctic temperatures, but the hemispheric temperature difference persists even in elevation-corrected data as shown in section 3. The main effect of the other factors will be a redistribution of energy within the Southern Hemisphere and can therefore not explain any difference between the hemispheres.

To assess the importance of polar temperature differences on the temperature difference, a simple test has been performed in which surface temperatures below the Antarctic Circle were replaced by their NH counterparts. For the surface air temperature data not corrected for elevation, this drastically reduces the interhemispheric temperature difference by $80 \%-90 \%$ in the three datasets described above. Much of this is driven by elevation, however, as can be directly seen from a comparison of Figs. 1 and 5. The corresponding reduction of the temperature difference in the elevation-corrected data is only $\sim 20 \%$. This simple estimate certainly overestimates the contribution of polar albedo differences to the observed interhemispheric temperature difference since factors other than albedo affect the polar temperature difference as well, not least the northward transport of heat by the overturning circulation.

To summarize, in the CERES-FT08 dataset (where the Southern Hemisphere receives about 0.2 PW more solar radiation at the top of the atmosphere) the $\mathrm{SH}$ reflects about $0.1 \mathrm{PW}$ more radiation back into space than the NH, resulting in a slightly larger (by roughly $0.1 \mathrm{PW}$ ) flow of solar energy into the climate system in

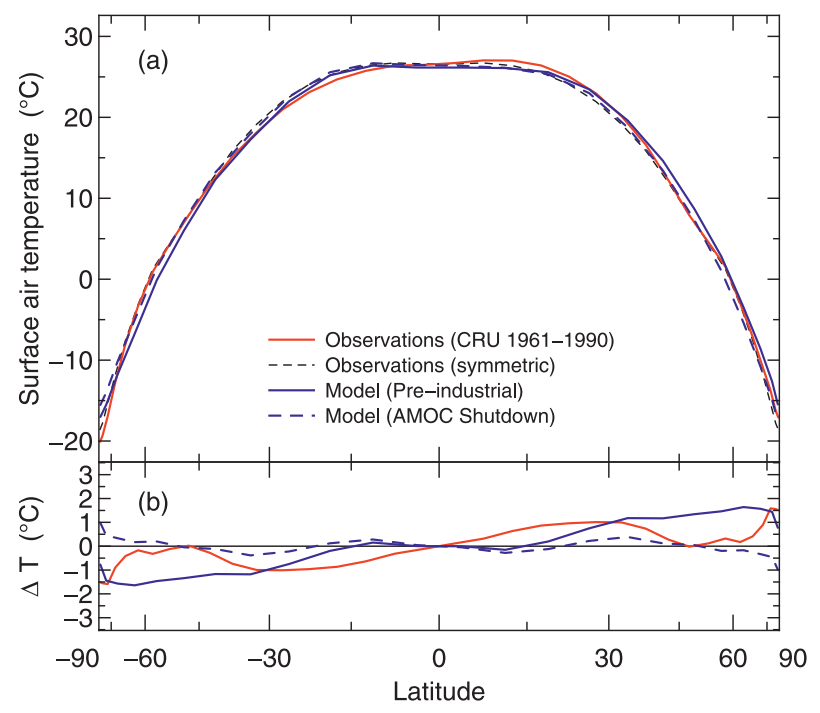

FIG. 5. (a) Surface air temperature as a function of latitude for data averaged over 1961-90 for the CRU climatology (red line) as well as the preindustrial climate simulation (solid blue line). As in Fig. 1, a symmetric version of the CRU temperature distribution constructed by taking the mean of the CRU temperatures in the $\mathrm{NH}$ and SH for each latitude is also shown (black dashed line) to highlight where the curves deviate from symmetry. The temperature distribution in the Atlantic meridional overturning circulation (AMOC) shutdown experiment is also indicated (blue dashed line). All temperature curves have been corrected for the effect of elevation. (b) As in (a), but showing the difference from a symmetrized temperature distribution for each dataset. Equal intervals on the latitude axis correspond to equal areas on the globe.

the Southern Hemisphere (see Table 2 for a summary). The energy budget of the hemispheres is given by the difference of this incoming solar radiation and the outgoing infrared radiation which will be discussed next.

\section{b. Longwave emission and radiative imbalance}

The net incoming solar radiation at the top of Earth's atmosphere (122.6 $\pm 0.2 \mathrm{PW}$ in the CERES-FT08 data, $2 \sigma$ uncertainty range) is (nearly) balanced by its emission of infrared radiation. The CERES-FT08 data show that $122.1 \pm 0.4 \mathrm{PW}$ are emitted globally per year, with $\mathrm{NH}$ emissions of $61.2 \mathrm{PW}$ exceeding the SH emissions of 60.9 PW by about $0.3 \mathrm{PW}$, which is of the same magnitude as the uncertainties. These slightly higher longwave emissions in the $\mathrm{NH}$ are a direct consequence of the higher surface-air temperatures in the Northern Hemisphere.

Model simulations and estimates of ocean heat content changes show that in today's changing climate the whole Earth absorbs more energy than it emits (Hansen et al. 2005). This global radiative imbalance totals $0.5 \pm 0.3 \mathrm{PW}$ per year and is generally used to constrain the global TOA balance of the CERES datasets. Interestingly, in terms of hemispheric flows the radiative imbalance is largely driven by the Southern Hemisphere in the 
CERES data: while it adds up to only $0.1 \mathrm{PW}$ north of the equator, the radiative imbalance amounts to $0.4 \mathrm{PW}$ in the Southern Hemisphere, with $2 \sigma$ uncertainties of about $0.3 \mathrm{PW}$. Note that this imbalance goes mostly into the ocean heat uptake and is hence expected to be larger in the Southern Hemisphere where there is more ocean.

\section{c. Summary}

In terms of the energy balance, a hemispheric temperature difference can be caused by three effects:

1) a difference in absorbed solar radiation,

2) a difference in outgoing longwave radiation, and

3) a cross-equatorial heat transport.

Each of these depends to some extent on the hemispheric temperatures, most notably the second since outgoing longwave radiation strongly depends on temperature and primarily acts as a negative feedback working to remove any hemispheric difference.

The effect of the cross-equatorial heat transport is special in that the overturning circulation in the oceans transports a large amount of heat from the colder to the warmer hemisphere, thereby promoting rather than damping the temperature difference.

The satellite data show that while both hemispheres absorb roughly equal amounts of solar energy, the Northern Hemisphere emits more longwave radiation to space, primarily due to its higher temperature. Without any northward energy transport, this would quickly diminish the observed temperature difference. Since the temperature difference has persisted at least over the twentieth century, however, it is reasonable to conclude that most of the net energy received by the Southern Hemisphere is transported to the Northern Hemisphere, either in the ocean or in the atmosphere. The meridional heat transport in the climate system will be investigated in detail in the following section.

\section{Meridional heat transport}

\section{a. Observational estimates}

The observed energy balance discussed above suggests the importance of meridional heat transport for the hemispheric temperature difference. Observationally, however, the meridional energy transport in the oceans and in the atmosphere is unfortunately only poorly constrained. One way to estimate ocean heat transport is from top-of-atmosphere observations of the atmospheric energy budget, with the ocean heat transport derived from the residuals. With this method, the mean annual meridional ocean heat transport across the equator has been estimated to amount to about $0.3 \pm$ 0.5 PW (Trenberth and Fasullo 2008).
Alternatively, the heat transport in the ocean can be estimated from direct hydrographic data in combination with geostrophic inverse models. Unfortunately, the transport across the equator cannot be determined with this method, but results from sections close to the equator suggest a total northward heat transport of $\sim 0.5 \mathrm{PW}$ (e.g., Ganachaud and Wunsch 2000, 2003; Wunsch 2005), with errors of about the same magnitude.

Finally, ocean heat transport can also be derived from ocean models forced by observations. One such study finds a total northward oceanic heat transport of $0.45 \pm$ $0.49 \mathrm{PW}$ at the equator (Zheng and Giese 2009), again in agreement with the other estimates.

In the energy budget studies, this northward heat transport in the oceans is nearly balanced, however, by a southward energy transport in the atmosphere of the same order of magnitude $(-0.2 \pm 0.5 \mathrm{PW})$, leaving a total energy across the equator to the north of roughly $0.1 \pm 0.5$ PW (Trenberth and Fasullo 2008).

While this analysis of energy fluxes derived from observations provides important insights and hints at the importance of northward energy transport in the oceans, it is not without problems. Most importantly, the uncertainties of the measurements are of the order of the total oceanic transport and of the energy difference between the hemispheres. In addition to these observational uncertainties there remain concerns due to the discrepancy between the observed solar radiation distribution in the satellite data and theoretical expectations. Furthermore, the large uncertainties in the derived meridional energy flows complicate the quest for the origin of the hemispheric temperature difference from observational data alone. Finally, from only a few years of measurements taken in a warming climate it is difficult to separate energy flows connected to hemispheric differences from imbalances resulting from ongoing climate changes. For these reasons, we complement this analysis by climate modeling experiments.

\section{b. Model experiments}

The model experiments have been performed with the coupled Earth system model of intermediate complexity Climate and Biosphere model $3 \alpha$ (CLIMBER-3 $\alpha$; Montoya et al. 2005). The model consists of an ocean general circulation model [the Modular Ocean Model, version 3 (MOM3); Pacanowski and Griffies 1999] with a horizontal resolution of $3.75^{\circ} \times 3.75^{\circ}$ and 24 vertical layers, coupled to a statistical-dynamical atmosphere describing the large-scale circulation patterns and their dynamical response to climate changes (Petoukhov et al. 2000). The atmosphere model has a horizontal resolution of $22.5^{\circ}$ in longitude and $7.5^{\circ}$ in latitude and uses 16 vertical layers. The coupled model also contains modules for the land surface interaction including vegetation 
(Petoukhov et al. 2000) and sea ice (Fichefet and Morales Maqueda 1997). The model has been used in a number of studies focusing on paleoclimate (e.g., Jansen et al. 2007; Feulner 2011), projections for the future (Feulner and Rahmstorf 2010; Schewe et al. 2011), investigations of the global meridional overturning circulation (Levermann et al. 2007; Schewe and Levermann 2010), and model intercomparison projects (Gregory et al. 2005; Stouffer et al. 2006; Eby et al. 2013; Zickfeld et al. 2013). In this study, we employ an improved version of the model [already used in Schewe and Levermann (2010)] with a very low background value of the vertical oceanic diffusivity $\left(0.3 \times 10^{-4} \mathrm{~m}^{2} \mathrm{~s}^{-1}\right)$ and a numerical advection scheme that largely eliminates numerical diffusion. This avoids the problems of an overly diffusive ocean causing artifacts in heat transport. The key advantage of this model for the present study is its computational efficiency, which allows the computation of thermodynamically equilibrated climate states (requiring many thousands of years of simulated climate).

As control simulation we use an equilibrium simulation of the preindustrial climate integrated for more than 50000 years. The maximum strength of the Atlantic meridional overturning in this simulation is $16.5 \mathrm{~Sv}$ $\left(1 \mathrm{~Sv} \equiv 10^{6} \mathrm{~m}^{3} \mathrm{~s}^{-1}\right)$ in good agreement with observational estimates (Ganachaud and Wunsch 2000). The average surface air temperature difference between the Northern and Southern Hemisphere in the preindustrial model experiment is about $1.5^{\circ} \mathrm{C}$, while a slightly larger value of $1.6^{\circ} \mathrm{C}$ is found for the period $1961-90$ in a transient run over the past millennium with natural and anthropogenic forcings as described in section 8 . These values for the temperature difference in the simulations are at the upper end of the measurements for the time period 1961-90 discussed in section 2. The somewhat larger values in the simulations can be explained from a slight overestimate of sea ice cover around Antarctica combined with a slight underestimate of Arctic sea ice area in the model used in this study (Montoya et al. 2005).

A comparison of the latitudinal distribution of the annually averaged surface-air temperatures in this simulation with observations is shown in Fig. 5. The temperatures from the model simulation are corrected for elevation in the same manner as the observational data (see section 3) using the topography map of the model. Both distributions show good general agreement.

To assess the importance of meridional heat transport in the oceans on the hemispheric surface air temperature difference, we perform simulations in which the Atlantic overturning is switched off by applying artificial freshwater input to the northern Atlantic deep-water formation regions. Starting from the equilibrium simulation described above, we slowly build up a negative salinity

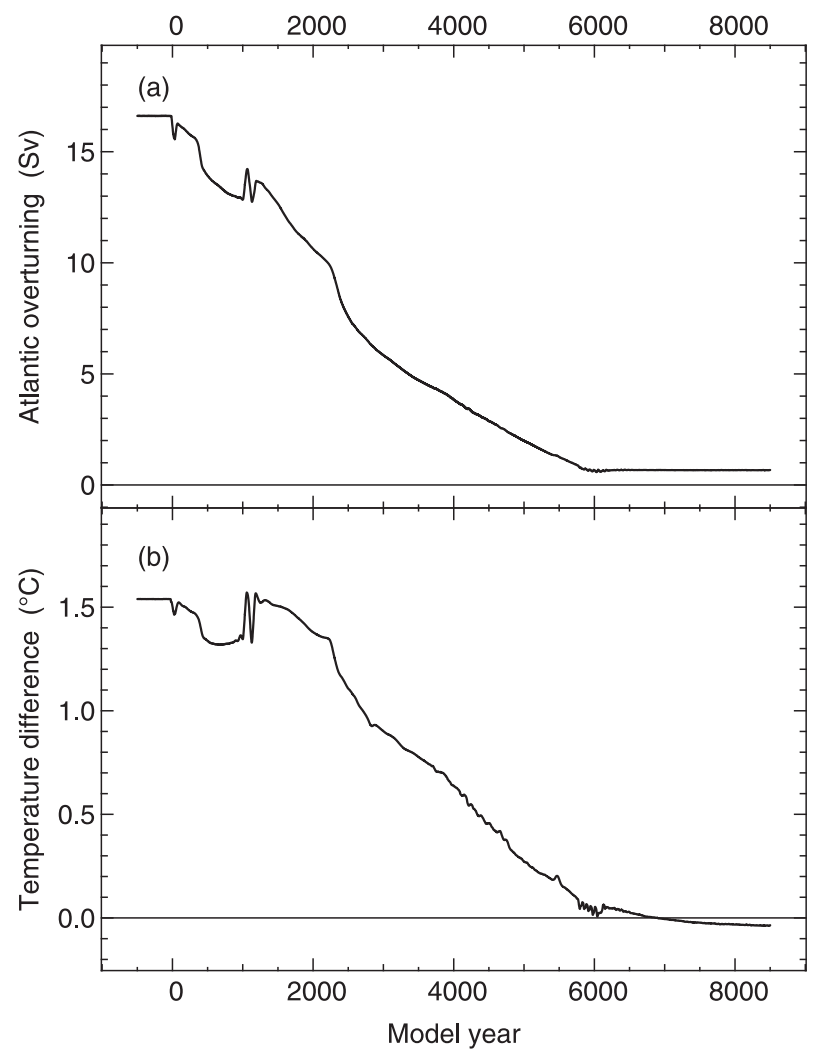

FIG. 6. (a) Maximum strength of the Atlantic overturning circulation and (b) the surface air temperature difference between the $\mathrm{NH}$ and $\mathrm{SH}$ for the freshwater-forcing model experiment. Both variables are plotted as a function of time; the zero point is defined by the beginning of the freshwater forcing in the simulation experiments. Both curves have been smoothed by a running mean with a width of 50 years.

forcing equivalent to $0.6-\mathrm{Sv}$ freshwater forcing over a period of 6000 years. This negative salinity forcing is applied in the part of the North Atlantic ranging from $52^{\circ}$ to $80^{\circ} \mathrm{N}$ and $48^{\circ} \mathrm{W}$ to $15^{\circ} \mathrm{E}$ and compensated by adding the same amount in the northern Pacific $\left(20^{\circ}-\right.$ $\left.50^{\circ} \mathrm{N}, 150^{\circ} \mathrm{W}-120^{\circ} \mathrm{E}\right)$. When the full forcing of $0.6 \mathrm{~Sv}$ is reached after 6000 years, the simulation is continued for more than 2000 years to ensure that a new equilibrium state is approached.

As shown in Fig. 6, the maximum strength of the Atlantic overturning circulation decreases from its initial value of $\sim 16.5 \mathrm{~Sv}$ to near zero in the new equilibrium state. In parallel, the surface air temperature difference between the hemispheres diminishes from $\sim+1.5^{\circ} \mathrm{C}$ to $\sim-0.05^{\circ} \mathrm{C}$. Switching off the overturning circulation thus effectively makes the temperature difference between the Northern and Southern Hemispheres disappear. The resulting latitudinal temperature distribution is shown in Fig. 5. The changes in temperature are almost symmetric about the equator and increase 

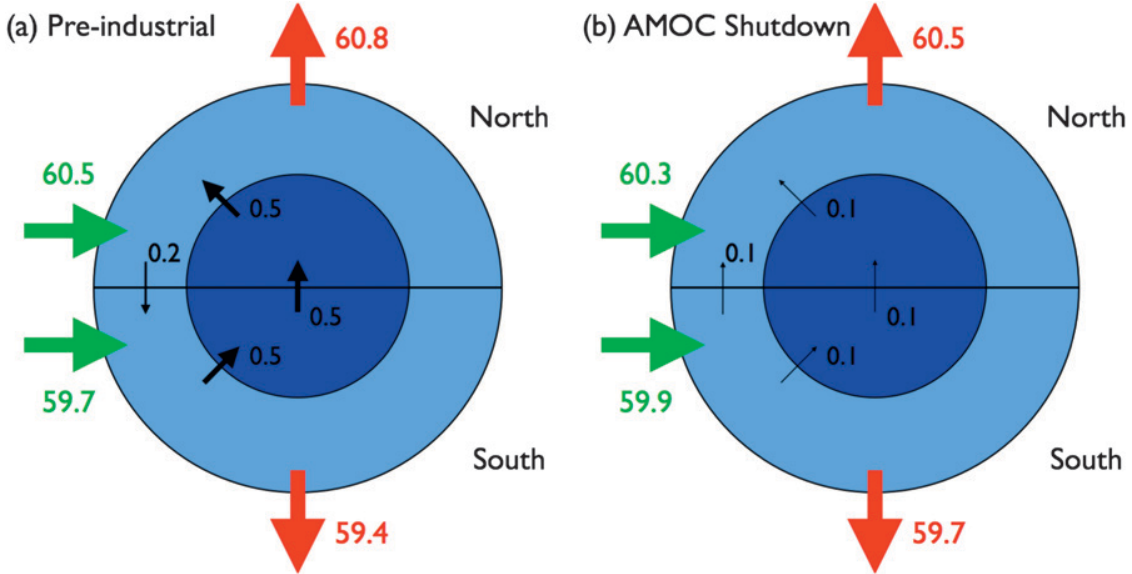

FIG. 7. Schematic diagram of the annual energy flows (in units of PW) for (a) the preindustrial and (b) the AMOC-shutdown simulations. The solar radiation absorbed by each hemisphere at the top of the atmosphere is shown in green, while the emitted longwave radiation is given in red. Net energy flows at the top of the atmosphere and the transport fluxes between the hemispheres in the atmosphere (light blue) and the ocean (dark blue) are indicated by the black arrows.

toward the poles where they reach absolute values of about $2^{\circ} \mathrm{C}$.

The annually averaged energy flows in both model experiments are shown in Fig. 7. In the control experiment for the preindustrial climate, the Northern Hemisphere emits $0.3 \mathrm{PW}$ more than it absorbs, while the situation is reversed in the Southern Hemisphere. The excess energy from the south is transported across the equator by ocean currents, pumping $0.5 \mathrm{PW}$ into the Northern Hemisphere. Furthermore, there is a much weaker atmospheric flux of $0.2 \mathrm{PW}$ back into the SH. Within the observational errors, these values agree with the satellite measurements discussed in section 6 .

After shutting down the overturning circulation, the absolute value of the radiative imbalance at the top of the atmosphere is reduced to $0.2 \mathrm{PW}$ for both hemispheres, and the oceanic heat transport is diminished to just $0.1 \mathrm{PW}$. The atmospheric transport is now of the same magnitude, but in contrast to the control simulation, it is now directed from the Southern to the Northern Hemisphere.

The absorbed solar radiation in the preindustrial model simulation also promotes the temperature difference (more energy is absorbed in the warmer Northern Hemisphere), but this is not supported by the satellite data discussed in section $7 \mathrm{a}$, which show-within the error limits-an equal absorption in both hemispheres (see also Table 2). Also, in the model this is not the cause of the hemispheric temperature difference, which vanishes in the model when the Atlantic meridional overturning is shut down.
Hence both the satellite data and the model support the conclusion that it is not a difference in absorbed solar radiation but primarily the northward ocean heat transport in the Atlantic that causes the Northern Hemisphere to be warmer than the Southern Hemisphere. This result confirms earlier findings of a strong influence of the overturning circulation on the temperature difference (Toggweiler and Bjornsson 2000; Vellinga and Wood 2002).

\section{Time evolution of the temperature difference}

Note that this paper has so far focused on the observed temperature difference between the hemispheres in present-day climate. The hemispheric difference may vary with time, of course. In this section, both the past and the possible future evolution of the temperature difference will be discussed.

\section{a. The past millennium}

Reconstructions of surface air temperatures over the past two millennia from various proxies show that the evolution of the difference is compatible with today's value within the error bars, but suggest a weak temporal pattern following the Northern Hemispheric temperature variations during this period of time (Mann and Jones 2003), with typical changes of $\sim 0.2^{\circ} \mathrm{C}$ between the Medieval Climate Anomaly and the Little Ice Age. Uncertainties are large, however, mainly due to the sparse proxy record for the Southern Hemisphere even in more recent compilations (Mann et al. 2008). 
Climate simulations for the past millennium (Feulner 2011) forced by variations in greenhouse gas concentrations [Schmidt et al. (2011) and Joos et al. (2001) for the preindustrial and industrial periods, respectively], changes in orbital parameters (Berger 1978), variability of the total solar irradiance [Steinhilber et al. (2009) before 1850; Wang et al. (2005) after 1850] and volcanic aerosols (Crowley 2000) exhibit a broadly similar behavior (see upper panel of Fig. 8), with a very similar amplitude of changes between warm and cool periods as compared to the reconstructions.

A comparison with diagnostics of the maximum strength of the Atlantic overturning circulation and Arctic sea ice cover (lower panel of Fig. 8) shows that the drop of the interhemispheric temperature difference in the sixteenth century goes hand in hand with a $\sim 5 \%$ decrease in the overturning circulation and an increase in Arctic sea ice of the same order of magnitude (see also Schleussner and Feulner 2013). The overturning remains low until the end of the twentieth century in these simulations, however, and the increase in the temperature difference after 1850 is then caused by the decrease in Arctic sea ice area due to global warming and the resulting albedo difference between the polar regions. The order of magnitude of the change in temperature difference due to changes in sea ice cover is consistent with the estimate for the contribution of polar albedo differences to the interhemispheric temperature contrast discussed in section 6 .

The additional contribution from the land-ocean warming contrast $\Delta T_{L} / \Delta T_{O}$ to the interhemispheric temperature difference can be estimated from the fractions of land $f_{L}$ and ocean $f_{O}$ in both hemispheres and the average warming over land $\Delta T_{L}$ and ocean $\Delta T_{O}:$

$$
\begin{aligned}
\Delta\left(T_{\mathrm{NH}}-T_{\mathrm{SH}}\right) & =\left(f_{L, \mathrm{NH}} \Delta T_{L, \mathrm{NH}}+f_{O, \mathrm{NH}} \Delta T_{O, \mathrm{NH}}\right)-\left(f_{L, \mathrm{SH}} \Delta T_{L, \mathrm{SH}}+f_{O, \mathrm{SH}} \Delta T_{O, \mathrm{SH}}\right) \\
& \approx \Delta T_{O}\left[\frac{\Delta T_{L}}{\Delta T_{O}}\left(f_{L, \mathrm{NH}}-f_{L, \mathrm{SH}}\right)+\left(f_{O, \mathrm{NH}}-f_{O, \mathrm{SH}}\right)\right] \simeq 0.2 \Delta T_{O}\left(\frac{\Delta T_{L}}{\Delta T_{O}}-1\right),
\end{aligned}
$$

where we have used $f_{L, \mathrm{NH}} \simeq 0.39$ and $f_{L, \mathrm{SH}} \simeq 0.19$ for the fraction of land in both hemispheres. For a land-ocean warming contrast of $\Delta T_{L} / \Delta T_{O} \simeq 1.3$ in our model and the observed value of $\Delta T_{O} \simeq 0.6^{\circ} \mathrm{C}$ over the twentieth century (Trenberth et al. 2007), the contribution of the stronger warming over land to the increasing interhemispheric temperature difference can be estimated to be $\sim 0.04^{\circ} \mathrm{C}$ or about $20 \%$ of the rise simulated for the twentieth century.

Note that the increase of the interhemispheric temperature difference during the twentieth century is likely overestimated in our model experiments because the cooling due to anthropogenic aerosol emissions is applied to be globally uniform whereas it predominantly affects the Northern Hemisphere in reality (Kiehl and Briegleb 1993).

\section{b. The future}

Future changes of the interhemispheric temperature difference until the year 2100 are explored for the representative concentration pathways (RCPs; Moss et al. 2010) using model simulations previously described in Feulner (2011).

As can be seen in Fig. 9, the increase of the temperature difference between the Northern and Southern Hemispheres under warming continues until $\sim 2020$ under all RCP scenarios. After this point, however, the RCPs considerably differ in their effect on the temperature difference. While the difference continues to rise to a maximum of $\sim 2^{\circ} \mathrm{C}$ around the year 2080 in the strong warming scenario RCP8.5, it declines to below $\sim 1.6^{\circ} \mathrm{C}$ by the end of the century in the stabilization scenario RCP2.6, with the other two RCPs between these extremes.

As for the changes of the temperature difference over the past millennium, this can be understood in terms of the competing effects of a decrease in the overturning circulation on the one hand and combined effect of the land-ocean warming contrast and Arctic sea ice loss on the other hand. For the lower RCPs the decrease in Atlantic overturning dominates and results in a decreasing interhemispheric temperature difference. For the RCP8.5 scenario, however, the increased warming over land and the melting of sea ice in the Arctic yields an increasing temperature difference between the hemispheres despite a reduction in overturning strength. The counterintuitive decrease of the interhemispheric temperature difference after $\sim 2015$ in the RCP2.6 scenario at roughly constant sea ice area and overturning strength is due to a decrease in ocean heat uptake in the Southern Ocean (not shown).

The contribution of the increased warming ratio over land discussed in section 1 to the future evolution of the interhemispheric temperature difference can be assessed by computing the land-ocean warming ratio in the time period 2081-2100 relative to 1981-2000 (with an average value of $\sim 1.3$ for the $\mathrm{RCP}$ simulations in our model) and artificially adjusting the warming over land 


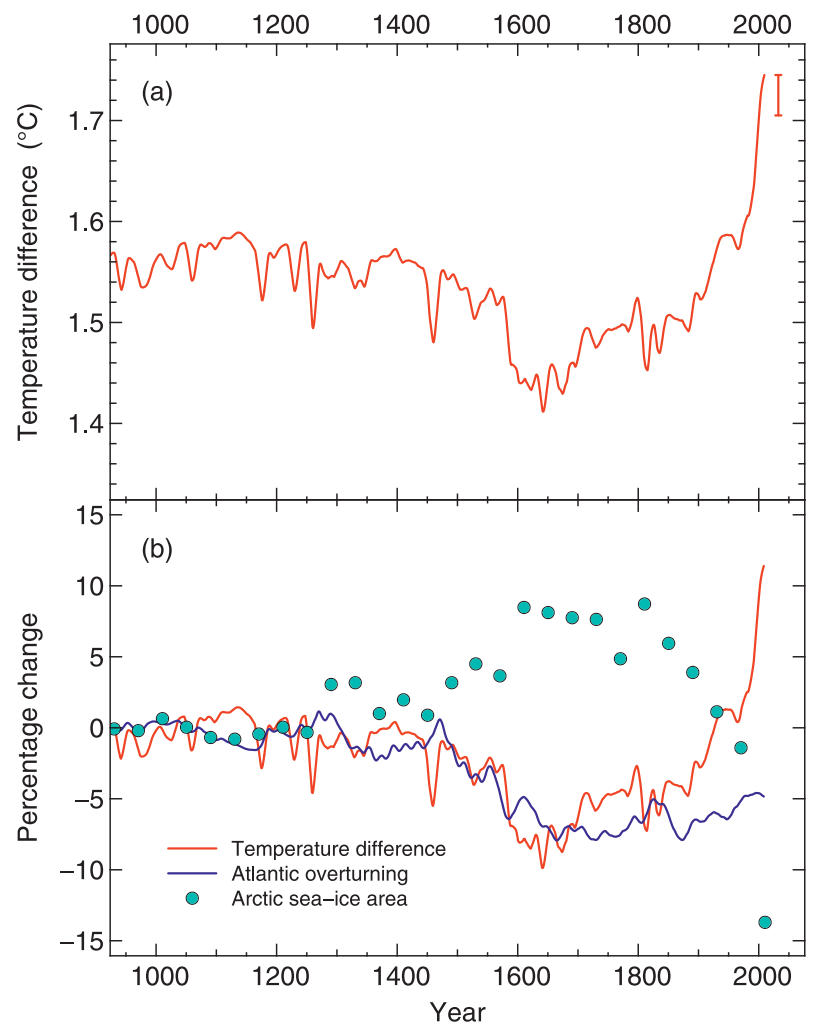

FIG. 8. (a) Time evolution of the surface air temperature difference between the $\mathrm{NH}$ and $\mathrm{SH}$ in a climate simulation over the past millennium. The curve has been smoothed using singular spectrum analysis (Ghil et al. 2002) with embedding $M=11$. The estimated contribution from the land-ocean warming contrast as discussed in the text is indicated by the red error bar to the right. (b) Percentage changes of the interhemispheric temperature difference (red line) compared to those of the maximum strength of the Atlantic meridional overturning circulation (blue line) and the Arctic sea ice cover (cyan circles). All percentage changes are expressed relative to the average in the time period 1000-1100; the curves have been smoothed as in (a).

by dividing the temperature change in land cells by this average land-ocean contrast before calculating the interhemispheric temperature difference. In this exercise, the temperature difference between the Northern and the Southern Hemispheres decreases by $0.02^{\circ}, 0.05^{\circ}$, $0.09^{\circ}$, and $0.14^{\circ} \mathrm{C}$ for RCP2.6, RCP4.5, RCP6, and RCP8.5, respectively, showing that the land-ocean contrast significantly contributes to twenty-first-century changes of the interhemispheric temperature difference for the higher RCPs. Estimates based on Eq. (2) yield similar values.

\section{Discussion and conclusions}

Climatological data clearly show that the average surface air temperature in the Northern Hemisphere is $1.2^{\circ}-1.5^{\circ} \mathrm{C}$ higher than in the Southern Hemisphere.

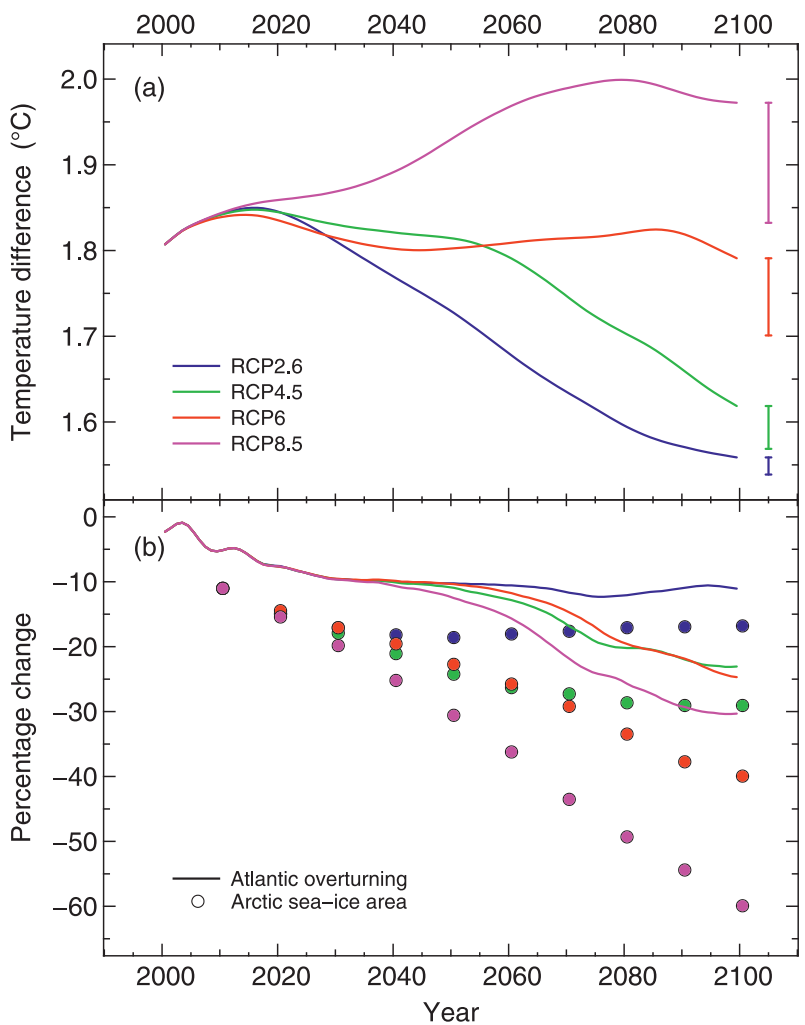

FIG. 9. (a) Future time evolution of the surface air temperature difference between the $\mathrm{NH}$ and $\mathrm{SH}$ in climate simulations forced by the representative concentration pathways (RCPs). All curves have been smoothed using singular spectrum analysis (Ghil et al. 2002) with embedding $M=11$. The estimated contributions from the land-ocean warming contrast as discussed in the text are indicated by the error bars to the right. (b) Percentage changes of the maximum strength of the Atlantic meridional overturning circulation (solid lines) and the Arctic sea ice cover (filled circles) for the RCPs shown in (a). All percentage changes are expressed relative to the average in the time period 1971-2000.

Historically, this temperature difference in the presentday climate has been attributed to a number of factors, including differences in seasonal hemispheric insolation, the distribution of landmass, the comparatively low temperatures over the Antarctic, and heat transport by oceans to the NH. Yet no detailed study has been performed so far to investigate if and to what extent these factors contribute to the hemispheric surface air temperature difference.

In this paper we use satellite observations of Earth's energy budget and simulations with a coupled climate model of intermediate complexity to answer the question as to why the Northern Hemisphere is warmer than the Southern Hemisphere.

In terms of energy balance, the interhemispheric temperature difference could be caused by 1 ) differences in absorbed solar radiation, 2) differences in 
emitted longwave radiation, and 3) northward heat transport across the equator. The satellite data show that both hemispheres absorb nearly equal amounts of solar radiation over the year, but show a clear surplus of emitted longwave radiation in the $\mathrm{NH}$. This is mainly a consequence of the higher temperatures in the Northern Hemisphere, of course, which acts as a negative feedback working to decrease the observed difference.

The observed cross-equatorial heat transport in the oceans is special in the sense that it transports heat from the colder Southern Hemisphere to the warmer Northern Hemisphere, thus actively enhancing the interhemispheric temperature difference. Indeed, both the satellite data and the model simulations demonstrate that the observed temperature difference between the hemispheres is largely due to this meridional energy transport in the oceans, with an additional contribution resulting from albedo differences between the Antarctic and the Arctic. Since these effects are partly coupled, and since the differences in energy flows are of the order of the uncertainties in the satellite observations and the climate model used in this study, their contribution of these two effects to the interhemispheric energy difference is difficult to quantify. Our best estimate would be that ocean heat transport and polar albedo differences contribute about $90 \%$ and $10 \%$ to the interhemispheric temperature difference in present-day climate. Note, however, that this estimate is based on the results of one model at comparatively low resolution. Other models might give different values, but in light of the discussion above a major contribution of oceanic heat transport to the observed warmer Northern Hemisphere appears likely. Recent paleoclimate evidence for a correlation between overturning strength and interhemispheric temperature difference during the last deglaciation constitutes further support for a dominant role of meridional ocean heat transport (Shakun et al. 2012).

Note that the explanation of the temperature difference based on ocean heat transport and albedo differences between the polar regions is consistent with the seasonal pattern described in section 2 . The fact that the difference is larger than the annual average in $\mathrm{NH}$ autumn (SON) and smaller than the annual average in spring (MAM) can be easily understood since the Atlantic overturning has a seasonal maximum in $\mathrm{NH}$ autumn (Kanzow et al. 2010), while Arctic sea ice area reaches its annual minimum around the same time (Barry et al. 1993), both enhancing the temperature difference.

Climate simulations over the past millennium demonstrate that the combined effect of changes in the overturning strength and in Arctic sea ice area result in the observed changes in the interhemispheric temperature difference. In the nineteenth and twentieth century, the difference also increases with global warming due to the loss of Arctic sea ice. Furthermore, the greater rate of recent warming experienced by the land surface enhances the temperature difference. Simulations for climate change in the twenty-first century under the representative concentration pathways (RCPs) show that the interhemispheric temperature difference continues to grow for the RCP8.5 scenario because of the landocean warming contrast and the strong loss of Arctic sea ice whereas the decrease in overturning strength dominates for the lower RCPs.

The combined effect of meridional transport of heat in the oceans and albedo differences between the Antarctic and the Arctic therefore is the main cause of the warmer Northern Hemisphere, but the discussion also highlights that much remains to be done to improve our understanding of Earth's energy budget, a task appearing even more important in today's changing climate.

Acknowledgments. The authors thank Hendrik Kienert and Vladimir Petoukhov for assistance and John Fasullo for interesting discussions and, together with Jessica Mackaro, for kind assistance with the CERES-FT08 data. We are grateful to the two anonymous reviewers for helpful comments. ECMWF ERA-40 data used in this study have been obtained from the ECMWF data server. The CERES-EBAF data were obtained from the NASA Langley Research Center Atmospheric Science Data Center. This research has made use of NASA's Astrophysics Data System Bibliographic Services.

\section{REFERENCES}

Barry, R. G., M. C. Serreze, J. A. Maslanik, and R. H. Preller, 1993: The Arctic sea ice-climate system: Observations and modeling. Rev. Geophys., 31, 397-422, doi:10.1029/ 93RG01998.

Berger, A. L., 1978: Long-term variations of daily insolation and quaternary climatic changes. J. Atmos. Sci., 35, $2362-$ 2367.

Chiang, J. C. H., and A. R. Friedman, 2012: Extratropical cooling, interhemispheric thermal gradients, and tropical climate change. Annu. Rev. Earth Planet. Sci., 40,383-412, doi:10.1146/ annurev-earth-042711-105545.

Croll, J., 1870: On ocean-currents. London Edinburgh Dublin Philos. Mag. J. Sci. (Fourth Series), 39, 81-106.

Crowley, T. J., 2000: Causes of climate change over the past 1000 years. Science, 289, 270-277, doi:10.1126/science.289.5477.270.

Eby, M., and Coauthors, 2013: Historical and idealized climate model experiments: An EMIC intercomparison. Climate Past, 9, 1111-1140, doi:10.5194/cp-9-1111-2013.

Fasullo, J. T., 2010: Robust land-ocean contrasts in energy and water cycle feedbacks. J. Climate, 23, 4677-4693.

, and K. E. Trenberth, 2008: The annual cycle of the energy budget. Part I: Global mean and land-ocean exchanges. J. Climate, 21, 2297-2312. 
Feulner, G., 2011: Are the most recent estimates for Maunder Minimum solar irradiance in agreement with temperature reconstructions? Geophys. Res. Lett., 38, L16706, doi:10.1029/ 2011 GL048529.

_ mum of solar activity on the future climate on Earth. Geophys. Res. Lett., 37, L05707, doi:10.1029/2010GL042710.

Fichefet, T., and M. A. Morales Maqueda, 1997: Sensitivity of a global sea ice model to the treatment of ice thermodynamics and dynamics. J. Geophys. Res., 102 (C6), 12 609-12 646.

Flohn, H., 1981: A hemispheric circulation asymmetry during late Tertiar. Geol. Rundsch., 70, 725-736, doi:10.1007/BF01822146.

Ganachaud, A., and C. Wunsch, 2000: Improved estimates of global ocean circulation, heat transport and mixing from hydrographic data. Nature, 408, 453-457, doi:10.1038/35044048.

_ transports during the World Ocean Circulation Experiment. J. Climate, 16, 696-705.

Ghil, M., and Coauthors, 2002: Advanced spectral methods for climatic time series. Rev. Geophys., 40, 1003, doi:10.1029/ 2000RG000092.

Gregory, J. M., and Coauthors, 2005: A model intercomparison of changes in the Atlantic thermohaline circulation in response to increasing atmospheric $\mathrm{CO}_{2}$ concentration. Geophys. Res. Lett., 32, L12703, doi:10.1029/2005GL023209.

Hansen, J., and Coauthors, 2005: Earth's energy imbalance: Confirmation and implications. Science, 308, 1431-1435, doi:10.1126/science.1110252.

Hartmann, D. L., M. E. Ockert-Bell, and M. L. Michelsen, 1992: The effect of cloud type on Earth's energy balance: Global analysis. J. Climate, 5, 1281-1304.

Harvey, G., 1834: A Treatise on Meteorology. London, 174 pp.

Jansen, E., and Coauthors, 2007: Palaeoclimate. Climate Change 2007: The Physical Science Basis, S. Solomon et al., Eds., Cambridge University Press, 433-497.

Jones, P. D., M. New, D. E. Parker, S. Martin, and I. G. Rigor, 1999: Surface air temperature and its changes over the past 150 years. Rev. Geophys., 37, 173-199, doi:10.1029/1999RG900002.

Joos, F., I. C. Prentice, S. Sitch, R. Meyer, G. Hooss, G. Plattner, S. Gerber, and K. Hasselmann, 2001: Global warming feedbacks on terrestrial carbon uptake under the Intergovernmental Panel on Climate Change (IPCC) emission scenarios. Global Biogeochem. Cycles, 15, 891-907, doi:10.1029/ 2000GB001375

Joshi, M. M., J. M. Gregory, M. J. Webb, D. M. H. Sexton, and T. C. Johns, 2008: Mechanisms for the land/sea warming contrast exhibited by simulations of climate change. Climate Dyn., $\mathbf{3 0}$, 455-465, doi:10.1007/s00382-007-0306-1.

Kalnay, E., and Coauthors, 1996: The NCEP/NCAR 40-Year Reanalysis Project. Bull. Amer. Meteor. Soc., 77, 437-471.

Kanzow, T., and Coauthors, 2010: Seasonal variability of the Atlantic meridional overturning circulation at $26.5^{\circ} \mathrm{N}$. J. Climate, 23, 5678-5698.

Kiehl, J. T., and B. P. Briegleb, 1993: The relative roles of sulfate aerosols and greenhouse gases in climate forcing. Science, $\mathbf{2 6 0}$, 311-314, doi:10.1126/science.260.5106.311.

King, J. C., and J. Turner, 1997: Antarctic Meteorology and Climatology. 1st ed. Cambridge University Press, 422 pp.

Kirwan, R., 1787: An Estimate of the Temperature of Different Latitudes. Peter Elmsly, London, 114 pp.

Lambert, F. H., and J. C. H. Chiang, 2007: Control of land-ocean temperature contrast by ocean heat uptake. Geophys. Res. Lett., 34, L13704, doi:10.1029/2007GL029755.
Lambert, J. H., 1779: Pyrometrie oder vom Maaße des Feuers und der Wärme. Haude \& Spener, 360 pp.

Levermann, A., J. Mignot, S. Nawrath, and S. Rahmstorf, 2007: The role of northern sea ice cover for the weakening of the thermohaline circulation under global warming. J. Climate, 20, 4160-4171.

Lockyer, W. S. J., 1906: Studies of temperature and pressure observations. Nature, 73, 594-595.

Loeb, N. G., B. A. Wielicki, D. R. Doelling, G. L. Smith, D. F. Keyes, S. Kato, N. Manalo-Smith, and T. Wong, 2009: Toward optimal closure of the earth's top-of-atmosphere radiation budget. J. Climate, 22, 748-766.

Loutre, M., D. Paillard, F. Vimeux, and E. Cortijo, 2004: Does mean annual insolation have the potential to change the climate? Earth Planet. Sci. Lett., 221, 1-14, doi:10.1016/ S0012-821X(04)00108-6.

Manabe, S., R. J. Stouffer, M. J. Spelman, and K. Bryan, 1991: Transient responses of a coupled ocean-atmosphere model to gradual changes of atmospheric $\mathrm{CO}_{2}$. Part I: Annual mean response. J. Climate, 4, 785-818.

Mann, M. E., and P. D. Jones, 2003: Global surface temperatures over the past two millennia. Geophys. Res. Lett., 30, 1820, doi:10.1029/2003GL017814

—, Z. Zhang, M. K. Hughes, R. S. Bradley, S. K. Miller, S. Rutherford, and F. Ni, 2008: Proxy-based reconstructions of hemispheric and global surface temperature variations over the past two millennia. Proc. Natl. Acad. Sci. USA, 105, 13252-13257, doi:10.1073/pnas.0805721105.

Milankovitch, M., 1941: Kanon der Erdbestrahlung und seine Anwendung auf das Eiszeitenproblem. Königlich Serbische Akademie, 633 pp.

Montoya, M., A. Griesel, A. Levermann, J. Mignot, M. Hofmann, A. Ganopolski, and S. Rahmstorf, 2005: The earth system model of intermediate complexity CLIMBER-3 $\alpha$. Part I: Description and performance for present-day conditions. Climate Dyn., 25, 237-263, doi:10.1007/s00382-005-0044-1.

Moss, R. H., and Coauthors, 2010: The next generation of scenarios for climate change research and assessment. Nature, 463, 747756, doi:10.1038/nature 08823 .

Pacanowski, R. C., and S. M. Griffies, 1999: The MOM-3 manual. NOAA/GFDL Ocean Group Tech. Rep. 4, 680 pp.

Petoukhov, V., A. Ganopolski, V. Brovkin, M. Claussen, A. Eliseev, C. Kubatzki, and S. Rahmstorf, 2000: CLIMBER-2: A climate system model of intermediate complexity. Part I: Model description and performance for present climate. Climate Dyn., 16, 1-17, doi:10.1007/PL00007919.

Philander, S. G. H., D. Gu, G. Lambert, T. Li, D. Halpern, N. Lau, and R. C. Pacanowski, 1996: Why the ITCZ is mostly north of the equator. J. Climate, 9, 2958-2972.

Schewe, J., and A. Levermann, 2010: The role of meridional density differences for a wind-driven overturning circulation. Climate Dyn., 34, 547-556, doi:10.1007/s00382-009-0572-1.

- _ - and M. Meinshausen, 2011: Climate change under a scenario near $1.5^{\circ} \mathrm{C}$ of global warming: Monsoon intensification, ocean warming and steric sea level rise. Earth System Dyn., 2, 25-35, doi:10.5194/esd-2-25-2011.

Schleussner, C. F., and G. Feulner, 2013: A volcanically triggered regime shift in the subpolar North Atlantic Ocean as a possible origin of the Little Ice Age. Climate Past, 9, 1321-1330, doi:10.5194/cp-9-1321-2013.

Schmidt, G. A., and Coauthors, 2011: Climate forcing reconstructions for use in PMIP simulations of the last 
millennium (v1.0). Geosci. Model Dev., 4, 33-45, doi:10.5194/ gmd-4-33-2011.

Shakun, J. C., and Coauthors, 2012: Global warming preceded by increasing carbon dioxide concentrations during the last deglaciation. Nature, 484, 49-55, doi:10.1038/nature10915.

Shimpo, A., and M. Kanamitsu, 2009: Planetary scale land-ocean contrast of near-surface air temperature and precipitation forced by present and future SSTs. J. Meteor. Soc. Japan, 87, 877-894, doi:10.2151/jmsj.87.877.

Steinhilber, F., J. Beer, and C. Fröhlich, 2009: Total solar irradiance during the Holocene. Geophys. Res. Lett., 36, L19704, doi:10.1029/2009GL040142.

Stouffer, R. J., S. Manabe, and K. Bryan, 1989: Interhemispheric asymmetry in climate response to a gradual increase of atmospheric $\mathrm{CO}_{2}$. Nature, 342, 660-662, doi:10.1038/342660a0.

— of the thermohaline circulation to past and future climate changes. J. Climate, 19, 1365-1387.

Sutton, R. T., B. Dong, and J. M. Gregory, 2007: Land/sea warming ratio in response to climate change: IPCC AR4 model results and comparison with observations. Geophys. Res. Lett., 34, L02701, doi:10.1029/2006GL028164.

Toggweiler, J. R., and H. Bjornsson, 2000: Drake Passage and palaeoclimate. J. Quat. Sci., 15, 319-328.

Trenberth, K. E., and J. T. Fasullo, 2008: An observational estimate of inferred ocean energy divergence. J. Phys. Oceanogr., 38, 984-999. , and Coauthors, 2007: Observations: Surface and atmospheric climate change. Climate Change 2007: The Physical Science Basis, S. Solomon et al., Eds., Cambridge University Press, 235-336.
Uppala, S. M., and Coauthors, 2005: The ERA-40 Re-Analysis. Quart. J. Roy. Meteor. Soc., 131, 2961-3012, doi:10.1256/qj.04.176.

Vellinga, M., and R. A. Wood, 2002: Global climatic impacts of a collapse of the Atlantic thermohaline circulation. Climatic Change, 54, 251-267, doi:10.1023/A:1016168827653.

von Humboldt, A., 1817: Des lignes isothermes et de la distribution de la chaleur sur le globe. Mémoires de physique et de chimie de la Société d'Arcueil, Vol. III, Société d'Arcueil, $145 \mathrm{pp}$.

Wang, Y., J. L. Lean, and N. R. Sheeley Jr., 2005: Modeling the sun's magnetic field and irradiance since 1713. Astrophys. J., 625, 522-538, doi:10.1086/429689.

Washington, W. M., and G. A. Meehl, 1989: Climate sensitivity due to increased $\mathrm{CO}_{2}$ : Experiments with a coupled atmosphere and ocean general circulation model. Climate Dyn., 4, 1-38, doi:10.1007/BF00207397.

Wielicki, B. A., B. R. Barkstrom, E. F. Harrison, R. B. Lee III, G. L. Smith, and J. E. Cooper, 1996: Clouds and the Earth's Radiant Energy System (CERES): An Earth Observing System Experiment. Bull. Amer. Meteor. Soc., 77, 853-868.

Wunsch, C., 2005: The total meridional heat flux and its oceanic and atmospheric partition. J. Climate, 18, 4374-4380.

Zenker, W., 1888: Die Vertheilung der Wärme auf der Erdoberfläche. Springer, $98 \mathrm{pp}$.

Zheng, Y., and B. S. Giese, 2009: Ocean heat transport in Simple Ocean Data Assimilation: Structure and mechanisms. J. Geophys. Res., 114, C11009, doi:10.1029/2008JC005190.

Zickfeld, K., and Coauthors, 2013: Long-term climate change commitment and reversibility: An EMIC intercomparison. J. Climate, 26, 5782-5809. 